\title{
Zinc Sulfate Could be a Potential Agent for the Treatment of Huntington's Disease Through Activating Central TrkB Signaling
}

To the Editor:

July 31, 2009

Huntington's disease (HD) is a neurodegenerative genetic disorder manifested by chorea and other hyperkinetic and hypokinetic movement disorders. Currently, there are no effective neuroprotective therapies for HD and symptomatic treatments, which are palliative in nature, remain the cornerstone of medical management.

One cardinal pathogenesis of HD is the degeneration of the striatal neurons, whose survival greatly depends on the binding of cortical brain-derived neurotrophic factor (BDNF) with its high-affinity receptor (TrkB). ${ }^{1}$ A postmortem study $^{2}$ demonstrated reduced BDNF expression in the striatum in HD when compared with agematched controls. In a recent study ${ }^{3}$ a reduction of TrkB receptors in HD mouse models and in the motor cortex and caudate nucleus of HD brains were found. From these findings, increasing central BDNF-TrkB signaling may have beneficial effects in the treatment of HD. Borrell-Pagès and colleagues ${ }^{4}$ have demonstrated that, by increasing BDNF levels in the brain, cysteamine is neuroprotective in HD mice. In another study, ${ }^{5}$ through adeno-associated viral vector-mediated gene transfer, enhanced expression of BDNF in the striatum was found to provide neuronal protection in a rodent model of HD.

Zinc is an essential co-factor for over 100 enzymes. Clinical studies ${ }^{6,7}$ have demonstrated the benefits of zinc sulfate monotherapy or supplementation for the treatment of attention-deficit/hyperactivity disorder and major depression, and it was well tolerated with a low rate of side effect. Chronic zinc treatment has been found to increase levels of BDNF mRNA in the rat cerebral cortex. ${ }^{8}$ Exposure to micromolar quantities of zinc robustly activated TrkB signaling in cultured cortical neurons. $^{9}$

Based on these findings, zinc sulfate, which could increase central BDNF levels or activate TrkB signaling, might be a potential agent for the treatment of HD. The author has conducted an extensive PubMed search of the published literature. However, no animal study or clinical trial has tested the therapeutic potential of zinc sulfate in HD. Recently, Sowa-Kuma and colleagues ${ }^{10}$ tested the antidepressant activity of zinc hydroaspartate in an animal model of depression and the effect of zinc treatment on BDNF protein and the mRNA level. They found zinc hydroaspartate exhibited a rapid antidepressant-like effect and zinc treatment induced a $17 \%$ to $39 \%$ increase in the BDNF mRNA and protein level in the hippocampus. ${ }^{10}$ Furthermore, Franco and colleagues ${ }^{11}$ indicated that chronic zinc treatment caused a significant antidepressant-like effect and produced an increase in BDNF expression in the cerebral cortex in rats.

These findings suggested that up-regulation of BDNF may be related to the antidepressant properties of zinc. ${ }^{11}$ Similarly, the potential therapeutic effect of zinc sulfate in HD patients can be evaluated in HD animal models such as mutant Huntington mice and may provide a new strategy for the treatment of this devastating disease.

Sincerely, Chia-Liang Wu, MD 


\section{REFERENCES}

1. Zuccato C, Cattaneo E. Role of brain-derived neurotrophic factor in Huntington's disease. Prog Neurobiol. 2007;81:294-330.

2. Ferrer I, Goutan E, Marín C, Rey MJ, Ribalta T. Brain-derived neurotrophic factor in Huntington disease. Brain Res. 2000;866:257-261.

3. Ginés S, Bosch M, Marco S, et al. Reduced expression of the TrkB receptor in Huntington's disease mouse models and in human brain. Eur J Neurosci. 2006;23:649-658.

4. Borrell-Pagès $M$, Canals JM, Cordelières FP, et al. Cystamine and cysteamine increase brain levels of BDNF in Huntington disease via HSJ1b and transglutaminase. J Clin Invest. 2006;116:1410-1424

5. Kells AP, Fong DM, Dragunow M, et al. AAV-mediated gene delivery of BDNF or GDNF is neuroprotective in a model of Huntington disease. Mol Ther. 2004;9:682-688.

6. Bilici M, Yildirim F, Kandil S, et al. Double-blind, placebo-controlled study of zinc sulfate in the treatment of attention deficit hyperactivity disorder. Prog Neuropsychopharmacol Biol Psychiatry. 2004:28:181-190.

7. Siwek M, Dudek D, Paul IA, et al. Zinc supplementation augments efficacy of imip- ramine in treatment resistant patients: A double blind, placebo-controlled study. $J$ Affect Disord. In press.

8. Nowak G, Legutko B, Szewczyk B, et al. Zinc treatment induces cortical brain-derived neurotrophic factor gene expression. Eur J Pharmacol. 2004;492:57-59.

9. Hwang JJ, Park MH, Choi SY, Koh JY. Activation of the Trk signaling pathway by extracellular zinc. Role of metalloproteinases. J Biol Chem. 2005;280:11995-12001.

10. Sowa-Kuma M, Legutko B, Szewczyk B, et al. Antidepressant-like activity of zinc: further behavioral and molecular evidence. J Neural Transm. 2008;115:1621-1628.

11. Franco JL, Posser T, Brocardo PS, et al. Involvement of glutathione, ERK1/2 phosphorylation and BDNF expression in the antidepressant-like effect of zinc in rats. Behav Brain Res. 2008;188:316-323.

Dr. Wu is a psychiatrist in the Department of Psychiatry at Taipei Veterans General Hospital in Taiwan.

Disclosure: The author does not have an affiliation with or financial interest in any organization that might pose a conflict of interest. 